\title{
Distilling Professional Opinion to Gauge Vulnerability of Guam Avifauna to Brown Treesnake Predation
}

\section{OPEN ACCESS}

Edited by:

Carlos R. Ruiz-Miranda,

State University of the North Fluminense Darcy Ribeiro, Brazil

Reviewed by:

Catherine Price,

The University of Sydney, Australia Bill Bateman,

Curtin University, Australia

*Correspondence:

Robert M. McElderry

mcelderryr@triton.uog.edu

${ }^{\dagger}$ Contracted to U.S. Department of Agriculture APHIS, Wildlife Services, National Wildlife Research Center, Barrigada, Guam

Specialty section: This article was submitted to Animal Conservation a section of the journal Frontiers in Conservation Science

Received: 22 March 2021 Accepted: 10 June 2021 Published: 08 July 2021

Citation: McElderry RM, Paxton EH, Nguyen AV and Siers SR (2021) Distilling

Professional Opinion to Gauge Vulnerability of Guam Avifauna to Brown Treesnake Predation.

Front. Conserv. Sci. 2:683964. doi: 10.3389/fcosc.2021.683964

\author{
Robert M. McElderry ${ }^{1 * t}$, Eben H. Paxton ${ }^{2}$, Andre V. Nguyen ${ }^{3}$ and Shane R. Siers ${ }^{4}$ \\ ${ }^{1}$ Research Corporation of the University of Guam, Mangilao, Guam, ${ }^{2}$ U.S. Geological Survey, Pacific Island Ecosystems \\ Research Center, Hawaii National Park, Hawaii, HI, United States, ${ }^{3}$ Department of Biology, University of Hawaii at Hilo, Hilo, \\ HI, United States, ${ }^{4}$ U.S. Department of Agriculture, Wildlife Services, National Wildlife Research Center, Barrigada, Guam
}

The avifauna of Guam was devastated by the introduction of the Brown Treesnake, and the restoration of native birds would need to address the problem with eradication or suppression of BTS. With eradication of the snake unlikely in the near term, and suppression capabilities limited to specific finite areas, key information for reintroductions is how low BTS abundance will likely need to be for each bird species to be re-established based on their vulnerability to BTS predation. Here, we estimate vulnerability, which can no longer be measured directly, so biologists who are familiar with one or more of seven Guam birds were surveyed to obtain their knowledge and produce quantitative vulnerability estimates. As is typical of birds adapted to islands devoid of predators, respondents judged that our focal species exhibit few predator avoidance and tolerance traits, leaving body size as the prime determinant of vulnerability. Respondent opinion also holds that any behavior that reduces the likelihood of an encounter by BTS, e.g., roosting/nesting in palm crowns, cavity nesting, and in particular urban dwelling, substantially reduces vulnerability. Our results can help inform species-specific decisions about when it may be safe to consider the release of birds on Guam depending on the relative vulnerability of each species to predation by BTS.

Keywords: non-native predator, invasive species, island endemic avifauna, predator-prey interactions, Mariana Islands, species reintroduction

\section{INTRODUCTION}

The accidental introduction of Brown Treesnakes (Boiga irregularis; BTS) in the 1940s to the Pacific island of Guam precipitated an unprecedented collapse of the island's entire forest avifauna (Savidge, 1987; Wiles et al., 2003; Rodda and Savidge, 2007). Guam and the other Mariana Islands had no native snakes or snake predators, and the proliferation of BTS after being introduced to Guam has led to the extinction/extirpation of almost all forest birds on the island (Savidge, 1987). BTS threaten the existence of forest birds, and although current BTS removal techniques are evolving (e.g., Nafus et al., 2020; Siers et al., 2020a,b), island-wide eradication is not feasible in the near future. Meanwhile, there are at least two initiatives in which avifauna once native to Guam and the Mariana Islands are being reared in captivity with the intent of reestablishing wild populations on Guam (Haig et al., 1990; Brock and Beauprez, 2000; MAC Working Group, 2014; Trask et al., 2021). However, these goals to reestablish avifauna once native to the island are hindered by the continued presence of BTS. 
Estimating the level of BTS suppression necessary to reduce predation rates to levels that allow the establishment and persistence of native birds on Guam is a multi-faceted problem. Introducing bird species in a landscape with too many snakes, and without mitigation of other threats, would be a waste of scarce resources, public capital, and needless suffering of individual birds (e.g., Fischer and Lindenmayer, 2000; Moseby et al., 2011). Unfortunately, because BTS and most of the native Guam bird species no longer co-exist, much of the necessary information on ecological interactions and predation risks does not exist and cannot be studied. Nonetheless, there is a need for informed predictions about predation risks to birds so that future bird reintroductions into areas inhabited by BTS at some suppressed level have higher chances of success (Yackel Adams et al., 2019). Therefore, we used expert opinion to provisionally bridge knowledge gaps. Expert knowledge to some degree supports all conservation decisions, and it is increasingly being gathered and focused to produce quantitative predictions (Sutherland, 2006; Martin et al., 2012). Where little or no data exist and circumstances prevent direct observation/experimentation, soliciting expert opinions can provide valuable information that can reduce uncertainty and inform adaptive management programs (Runge et al., 2011), and in our case, it provides a means for predicting the relative vulnerability of Guam birds to reduced levels of BTS predation.

In this study, we solicited the views of biologists who have worked extensively with Guam avifauna to synthesize expert opinions regarding bird-snake interactions for which we have limited formal knowledge and almost no capacity for field or captive studies. Focusing on seven promising candidate bird species for reintroduction, we developed a questionnaire to answer four broad questions: (i) Relative to a baseline BTS presence (described below), how likely is each bird species to be encountered by a BTS? (ii) Which life stages within a family unit may be at risk during a single BTS encounter? (iii) How likely is an individual to be killed during an encounter? (iv) How do various bird and snake life stages/sizes affect the outcome of an encounter? Our results provide a metric by which bird species may be ranked for reintroduction according to their vulnerability to predation by BTS. These rankings can help prioritize species for reintroduction based on attainable levels of BTS control and can help provide insights on what management actions may be best suited for the successful reestablishment of Guam's avifauna.

\section{METHODS}

\section{Study Species}

Among the avifauna extirpated from Guam by BTS predation, we focused here on the following: Ko'ko' (Guam Rail) Gallirallus owstoni, Åga (Mariana Crow) Corvus kubaryi, Totot (Mariana Fruit-Dove) Ptilinopus roseicapilla, Sihek (Micronesian Kingfisher) Todiramphus cinnamominus, Chichirika (Rufous Fantail) Rhipidura rufifrons, and Nosa' (Bridled White-eye) Zosterops conspicillatus. Såli (Micronesian Starling) Aplonis opaca still persists on Guam, but only on a small fraction of its historic range, and largely in urban habitats (Pollock et al., 2021). These seven candidate species are being considered for reintroduction due to the maintenance of captive breeding programs or appropriate source populations on nearby islands (Haig et al., 1990; Brock and Beauprez, 2000; MAC Working Group, 2014; Trask et al., 2021).

Without a comprehensive description of predator avoidance and tolerance traits for Guam birds, we composed two questions that asked experts to compile a list of predator (i.e., BTS) avoidance and tolerance traits for each bird. We review relevant species biological details along with our results from these two questions.

\section{Questionnaire}

A survey was developed (see Supplementary Material) to collect the opinions of biologists who are very familiar with some or all of these birds in terms of how each bird's physical, behavioral and life history traits might influence their risk of predation by BTS. The participation of 41 biologists (ornithologists and herpetologists) who were identified as working extensively with one or more of our focal species was solicited through the University of Guam. Nineteen of these biologists (including one author, SS) participated in the survey (hereafter "respondents"). All respondents are very familiar with the BTS problem on Guam and have devoted at least part of their careers toward researching the threat of BTS to Guam birds. Respondents were asked to use their judgment to rate various dimensions of risk associated with each bird species. We then converted these ordinal ranked responses to a numeric scale.

\section{Dimensions of BTS Predation}

We divided BTS predation risk into two dimensions: the risk of encounter and the risk of death given an encounter. The risk of being encountered by a BTS may vary among avifauna due to one or more of many possible predator and prey trait combinations. We asked respondents to rank encounter rates among avifauna relative to a baseline rate, such as might be determined by the BTS contact rate at live lure camera traps in an area (e.g., Siers, accepted; Yackel Adams et al., 2019). Live lure camera traps use a live bird or mouse to lure BTS. Baseline encounter rates are likely affected by local snake density and size distribution, neither of which are well-known. We also asked respondents to identify what traits may be possessed by each species that either increase or decrease their risk of encounters relative to this baseline rate. Each encounter with a BTS is potentially fatal, whether the bird is consumed or not, and the fate of each bird may depend on the size of the snake and their own life stage, body size, other species level traits. We crafted several questions to distill expert opinions concerning the fate of encountered birds and the traits they possess that may mitigate the risk of death. In most questions we asked respondents to consider a mature snake, defined as a BTS larger than average (1,050-1,200 mm snout-vent-length), but smaller than the largest snakes. We also provided six BTS size ranges, from hatchling to extremely large adult, and asked respondents to consider how BTS size variation would modulate the expected outcome for an encountered adult bird. 


\section{Rescaling of Risk}

Our goal was to represent predation risks as probabilities for subsequent risk assessments and modeling. Rather than ask respondents initially for quantitative judgements, we asked for rankings that we later converted to numeric probabilities. For example, we asked respondents to select among five risk levels (much more, more, same, less, and much less than baseline) to estimate the chances that each bird would be encountered by a BTS. All our focal birds are highly susceptible to encounter by BTS, so we equated this ordinal scale to a proportional scale over a dampened range, $\pm 20 \%$ of a baseline probability of BTS encounter. Within a family unit, we asked which life stages would share the risk of predation when an adult bird is encountered by a mature BTS (e.g., mates or nestlings). For example, Savidge (1987) reported a single BTS consuming multiple Nosa' within a roosting group while they slept. Converting yes or no responses to 1 or 0 , the average of all responses represents the proportional consensus that there is a shared risk, and if all respondents replied "yes," we calculate 1.0 as the probability of shared risk, and this family member (e.g., nestlings) would always be encountered when its parent is encountered.

To elucidate the intricacies of death risk on encounter while keeping questions relatively simple, we composed multiple focused questions and then amalgamated their results. For adults only, we asked respondents to rank mortality risk on encounter using a five-point scale from certain survival to certain death, which we translated into a probability from 0 to 1 . Rather than ask respondents to do this same task for all life stages, we asked them to rank life stages relative to one another in terms of vulnerability in an encounter. We summarized these rankings from least to most at risk, and then scaled all stage specific values proportionally so that adult risk of death matched those described above while maintaining egg/nestling risk of death relatively unchanged, as they were already very near to one. For the adult partner of an initially encountered adult bird, we asked respondents to rate the risk of death for the partner (no risk to equal risk) against the risk for the adult initially encountered. Proportional in nature, the product of this metric with adult (and adult on nest) risk of death on encounter represents adult (and adult on nest) risk of death given a partner's encounter with a BTS.

To integrate predation risk over the lifetimes of these birds, and generate a single vulnerability ranking, we defined a standard developmental progression from age 0 to 5 years and calculated the risk of death by BTS at each age. In 2-month timesteps, each bird is first in the nest, then a fledgling, a juvenile for three timesteps, and then an adult from 1 to 5 years of age. Most of these birds reach adulthood, or at least appear adult like, by 1 year of age. We set adults to be on nest every third timestep (twice per year). With this common life cycle, we then calculated the probability of being encountered and killed at each age as the stage specific death risk on encounter for each age multiplied by the encounter risk. The probability of surviving each age is one minus the probability of being encountered and killed by BTS. The full probability of being killed by BTS at each age is then the product of all survival probabilities up to the age of death and the probability of death at that age. The sum of these probabilities of being killed by BTS at each age yields the lifetime cumulative likelihood of being killed by BTS at or before each age class.

\section{Level of Expertise}

With varied expertise among our respondents, we asked them to report their level of expertise for each focal avifauna. We used self-assessed expertise rankings (no knowledge to expert in five levels) to weight responses such that expert opinions were four times as informative as those from barely familiar respondents. Respondents did not provide input for avifauna of which they had no knowledge.

\section{RESULTS}

All respondents ranked themselves as very familiar or expert for at least one species, and many were self-assessed experts in several species. On average, respondents ranked themselves from familiar to very familiar; with the highest ranking indicating that our respondents feel most knowledgeable (very familiar) about BTS.

\section{What Are the Relative Risks of Being Encountered by a BTS?}

Respondents agreed on specific attributes that varied among bird species and contributed to their risk of being encountered by a BTS (Figure 1). In order of decreasing risk, smaller birds Nosa' and Chichirika had an elevated risk over mid-sized birds Totot and Sihek, which were at higher risk than the largest birds Ko'ko' and Åga, that were notably not ranked as low risk along with the mid-sized bird Såli (Figure 1A). Overall encounter risk decreased with increasing adult bird body size with a few notable exceptions that were adequately explained by predator avoidance traits possessed by these birds (see below).

Respondents listed several bird traits that are known or suspected to reduce the risk of BTS encounters relative to other focal bird species. Birds with no anti-predator traits reported (Nosa', Chichirika) were ranked higher than baseline encounters. Bill and body size (Åga, Ko'ko', Sihek) were frequently listed as deterrents to BTS encounters, as was the quiet and inconspicuous nature of Totot that readily flush from their nests. Roosting in isolated coconut palms (Såli) or nesting in super canopy trees (Åga), on thin branches far from the trunk (Totot), within coconut trunks (Sihek), cavities (Såli and Sihek), cliff faces, cave entrances, and artificial structures (Såli) were identified by many respondents as key factors that may deter BTS encounters. Separate roost and nest sites when not actively incubating or brooding and leaving nestlings and fledglings alone at night (Åga) may also reduce encounter risk. Urban dwelling (Såli) and tolerance to urbanization (Ko'ko') were also identified as BTS encounter deterring traits, as was ground dwelling (Ko'ko'). Finally, intelligence and sociality (Åga and Såli) were identified along with alarm calls (Åga) and communal roosting of juveniles (Såli) as deterrents to encounters by the BTS. 


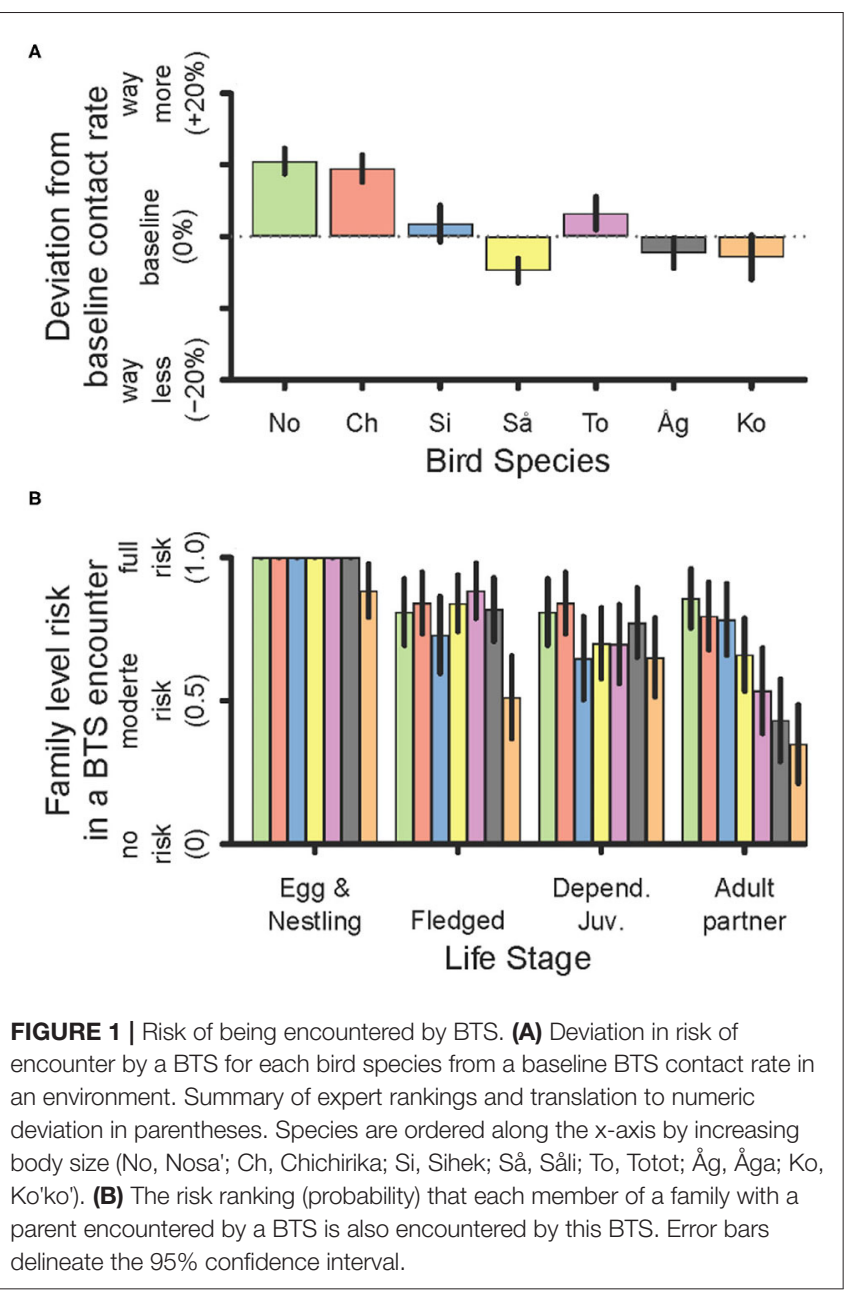

\section{Which Birds Are at Risk in an Encounter?}

The risk of death during a single encounter with BTS is shared among family members. Respondents demonstrated their expert consensus that the level of risk drops with increasing size among life stages within each species, and this risk drops more strongly for birds with larger adult size (Figure 1B). Note here that we consider this a probability of being at risk, and if yes, then there is a probability of death, which we describe below.

\section{What Is the Risk of Death for Each Life Stage?}

The chance of death on encounter with a BTS decreased with increasing bird size, with some notable exceptions. Both Sihek and Åga had lower risk of death on encounter than would be predicted by their adult size alone (Figure 2A). Within a species, smaller less developed stages, e.g., eggs, nestlings, and fledglings were the most vulnerable (Figure 2B). Adults were the least vulnerable. Juveniles were intermediately vulnerable, and adults on a nest were notably more vulnerable than juveniles for some species (Figure 2B). Relative to an adult bird encountered initially, its partner has less than equal risk of death, a proportion that declines to about half risk for larger birds (Figure 2C). Integrating all three of these components, we propose a stage specific probability of death for each species shown in Figure 2D.

Most notable in terms of predator defense ability is Ko'ko.' Body and bill size were frequently listed as predator defense traits for Ko'ko', Åga, and sometimes Sihek. Åga was reported to be aggressive toward predators. Respondents noted Åga's intelligence, and its tendency toward alarm calling and mobbing in the presence of a predator. Predatory instincts were also listed for Ko'ko', Åga, and Sihek as a possibly favorable trait for predator defense. Also reported to be aggressive toward predators were Såli and Sihek, and Sali may also use alarm calls to alert neighboring birds of threats. It was suggested that Ko'ko' may outrun BTS. However, we note that BTS is a nocturnal predator, and how these birds may behave at night is not well known. Sali was reported to be skittish on its nest at night and easily flushed, and respondents suggested Åga may also flee a predator at night. However, one respondent shared an observation of Åga remaining calm at night while snakes invaded their nests.

Expert consensus reflects that the risk of death for a bird encountered by a BTS depends strongly on the body size of the snake (Figure 3). We found that small snakes, in the size range of hatchlings and juveniles posed little risk to all but the smallest of birds. On the other hand, large snakes were predicted to kill almost any sized bird it may encounter.

The cumulative lifetime vulnerability ranking integrates the risk of predation by BTS over a common theoretical lifetime for each bird species (Figure 4). While largely recapitulating the patterns displayed above (Figure 2A), this metric clarifies that Totot is most vulnerable and Sihek is least vulnerable of the three mid-sized birds (Figure 4). It also clearly ranks Åga as the least vulnerable of these seven bird species. Although the magnitude by which these species differ in vulnerability to BTS depends strongly on the encounter rate and on how far we project over a bird's lifetime (results not shown), the ranking among species does not change (Figure 4).

\section{DISCUSSION}

Part of the decision of when, or if, to release birds into areas where BTS are suppressed can be informed by knowing what level of BTS presence each bird species may withstand. While we know that BTS extirpated nearly all forest birds on Guam over several decades (Wiles et al., 2003), we have few quantitative details concerning snake-bird interactions and lack a comprehensive way of predicting the effects of BTS on Guam birds. Scientists who have firsthand experience working with one or more of our focal native Guam avian species were surveyed, and we produced a means for quantifying the vulnerability of each bird species to predation by BTS. Overall, our expert respondents reported that smaller birds are thought to be both more likely to be encountered and more vulnerable in an encounter than larger birds. However, we also found that a few birds are thought to possess predator avoidance and tolerance traits that may reduce the risks posed by BTS. Ultimately, our results provide risk metrics that may be used in quantitative risk assessments to 


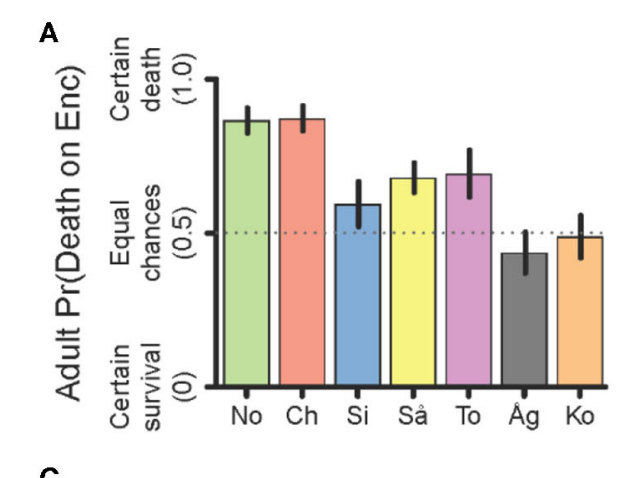

c

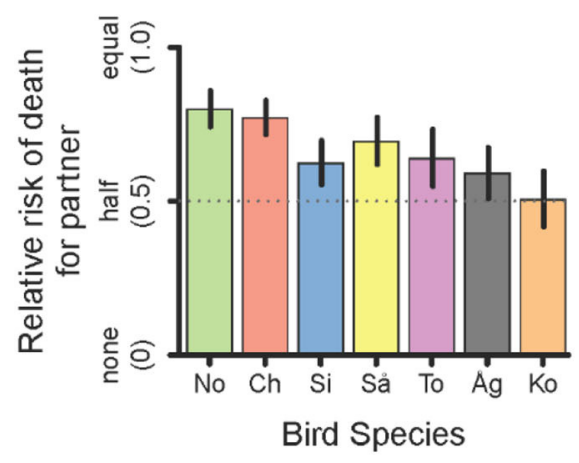

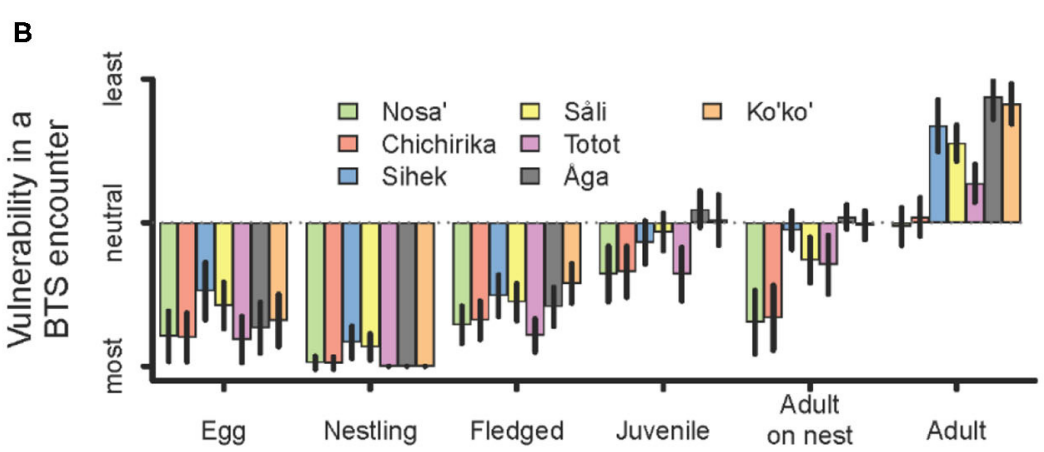

D

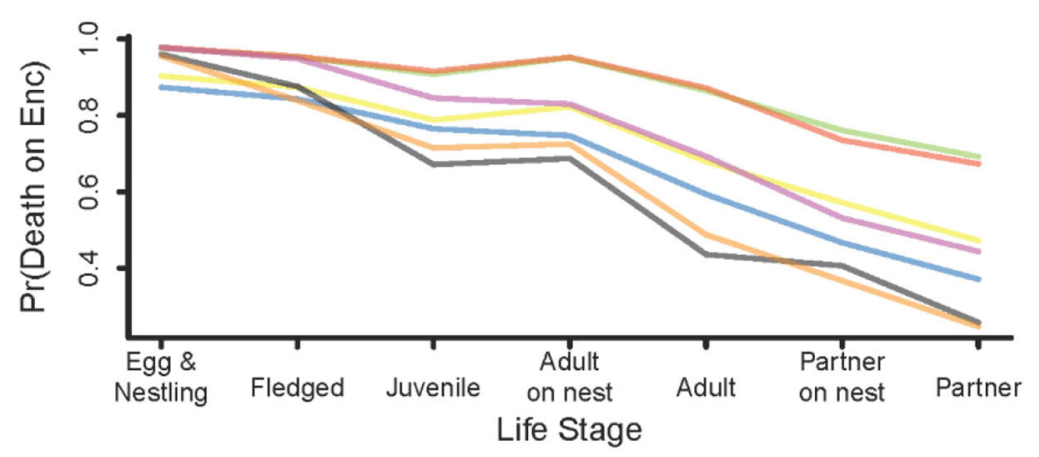

FIGURE 2 | Components determining risk of death in an encounter with a BTS. (A) Ranking (probability) of death for an initially encountered adult. (B) Relative vulnerability ranking among bird life stages. (C) Relative risk ranking (probability) of death for the partner of a bird initially encountered. Error bars delineate the 95\% Cl. (D) Composite measure of the bird-stage-specific probability of death for a bird encountered by a BTS. Birds in (A) through (C) are listed along the X-axis in order of increasing size (No = Nosa', Ch = Chichirika, Si = Sihek, Så = Såli, To = Totot, Åg = Åga, Ko = Ko'ko').

predict the susceptibility of birds to predation by BTS, which could guide the formulation of sensitivity and prioritization rankings among native Guam avifauna and help to determine required BTS suppression thresholds for bird persistence.

Of our seven focal avifauna, Chichirika and Nosa' were identified by our respondents as the most vulnerable. Both birds prefer forests (Jenkins, 1983), the preferred habitat for BTS, and are small enough to be susceptible to attack even by small BTS, which are the most numerous size class. Adults of these species are most at risk at night, when they roost in relatively exposed locations and at times in pairs and while incubating nests (Amidon et al., 2004; Nietmann and Ha, 2018). Like the Rota White-eyes (Zosterops rotensis), Nosa' may forage and roost in flocks, which likely places several birds at risk of predation during a single encounter (Savidge, 1987).

As a relatively large bird, Totot adults may be able to escape predation by smaller snakes, but they are forest specialists (Jenkins, 1983) and are therefore at high risk. Our respondents believe that Totot would be most vulnerable while roosting or on nest, but there is scant data for Totot. Its early disappearance from Guam (see Wiles et al., 2003) corroborates our finding that Totot is highly vulnerable to BTS and it may also suggest vulnerability to small snakes despite its size. Current work with Såli on Guam has revealed that many radio-tagged birds have been killed by snakes that were too small to consume them
(Pollock et al., 2019). Furthermore, snakes too small to consume or kill adults may also attack nests and reduce reproductive success (Savidge, 1987), which could have contributed to Totot's rapid decline. However, fully understanding the effect of BTS at the population level would require linking our individual-level risks to such vital rates as fecundity, which can be included in future work.

Best exemplifying the extreme threat posed by BTS to forest birds, the least vulnerable bird that we considered, Aga, was ultimately extirpated from Guam by BTS. Åga was in fact the last to disappear from Guam (U.S. Fish Wildlife Service, 2005), which demonstrates some tolerance of BTS. Our results suggest that individual Åga adults would be the most likely to survive in the presence of BTS, while Åga eggs and nestlings are just as vulnerable as those of other birds. Here again, reduction in reproductive success could have also been crucial in Åga's decline (Plentovich et al., 2005; U.S. Fish Wildlife Service, 2005; Zarones et al., 2015), but there are few data to guide us here. Despite Åga's propensity for alarm calls and mobbing like other corvids, one of our respondents shared an observation of a female Åga being flushed from her nest at night and remaining calm in the presence of a BTS. This snake failed to eat her egg, but dropped and broke it, nonetheless. How Åga and other birds behave during the day, when they were being observed by researchers, may be different from their behavior at night when BTS forage. 


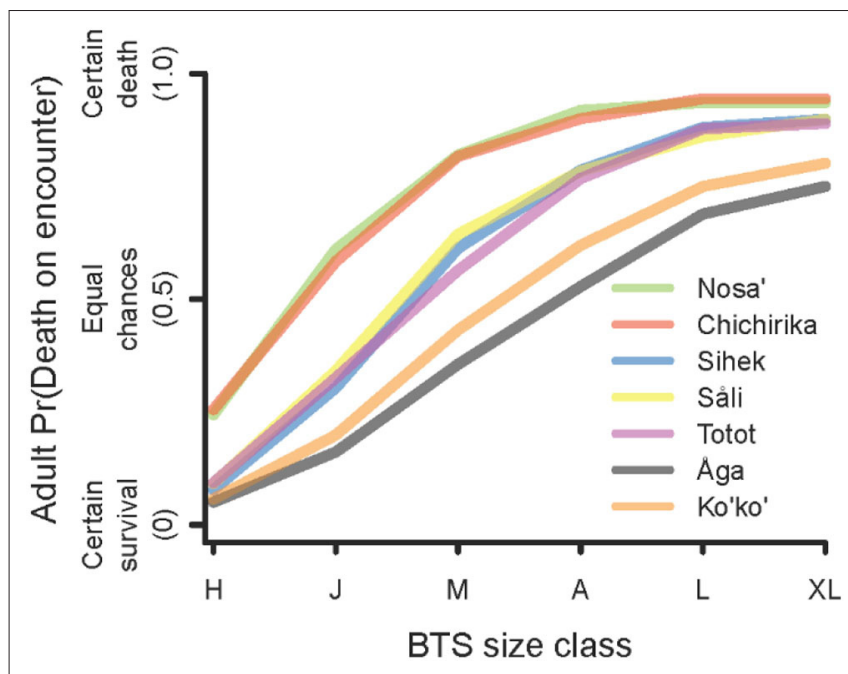

FIGURE 3 | Risk ranking (probability of death) for an adult bird in an encounter with a BTS for each snake size class: $\mathrm{H}$, hatchling (350-700 mm snout-vent length); J, juvenile (700-900); M, mature (900-1050); A, adult (1050-1200); L, large adult (1200-1500); XL, extra-large adult (>1500).

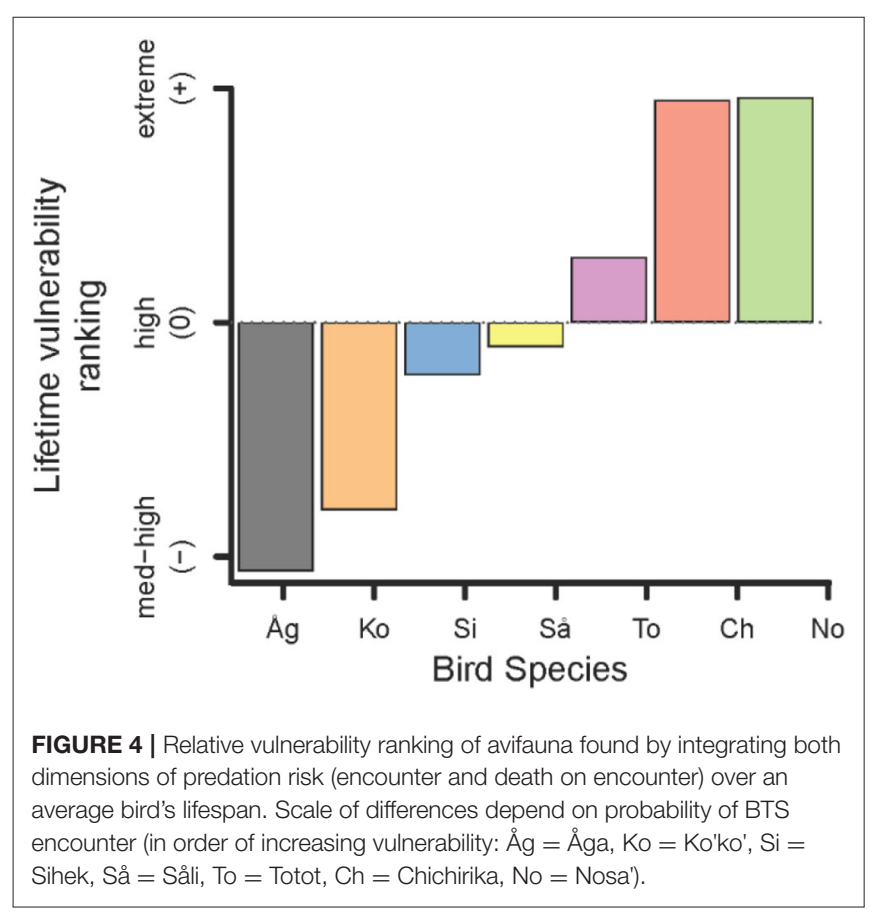

Size and aggression were commonly identified as deterrents to BTS predation. As the largest of our focal birds, Ko'ko' was ranked next to least vulnerable in the survey. Bill and body size were commonly listed for Åga, Ko'ko', and Sihek as traits that may reduce both the probabilities of being encountered and of being killed given an encounter. Although there may have been some confusion among respondents in interpreting our separation of encounter risk from death risk during an encounter, we note the possibility that snakes may adjust their search image after encountering prey that are too large to consume and/or that fiercely counterattack, but this is purely speculative. In terms of habitat preference, Ko'ko' are less likely than other birds to be encountered by BTS, because they nest and forage on the ground (Jenkins, 1979). However, large BTS are less arboreal and are more frequently found in savannas than smaller BTS (Rodda and Reed, 2007; Siers, 2015; Siers et al., 2017b), which may indicate that Ko'ko' would be more likely to be encountered by large BTS that are capable of consuming adult Ko'ko' (Savidge, 1988).

When we achieve lower BTS abundance levels, the possibility for deterring BTS-bird encounters using misinformation may become more realistic. Similar to work by Norbury et al. (2021), training BTS to interpret bird prey cues as unfruitful prey trails could reduce predation rates. The list of antipredator traits produced by our respondents suggest that these birds may not be completely naïve to predators (sensu Banks and Dickman, 2007), but BTS is a nocturnal predator and these birds are diurnal. Training adults to recognize specific predators as threats appears in some cases to improve survival of captive animals released into the wild (Heezik et al., 1999; White et al., 2005; West et al., 2018), but the ability to recognize BTS as a predator may be of little use to prey that are attacked while sleeping. Such training could improve the success rate of initial bird releases, but whether or not this training would be translated to subsequent generations is debatable.

Predator avoidance may be the best way to persist with a predator as voracious as BTS. As evidence, Såli was ranked the most elusive to BTS and is the only of these seven birds persisting in Guam. Åga received the second lowest encounter ranking, as well as the highest survivability ranking in a BTS encounter, which may explain how Åga outlasted most other species in the wild. However, Åga's eventual extirpation suggests that avoiding encounters just slows the rate of decline and does not alone ensure long-term persistence. Sali appears to be effectively avoiding BTS by adapting to urban areas, where snake densities are lower than in forests, and by nesting in cavities that may be more difficult for BTS to access. Cavity nesting itself does not seem to deter nest predation by snakes (e.g., Berkunsky et al., 2011), but cavities in large diameter poles without adjacent branches, e.g., solitary coconut palms, tall telephone poles, and other anthropogenic structures may be inaccessible to BTS (Savidge et al., 2018; Pollock et al., 2021). Sihek also nests in cavities, but exclusively in the forest in decaying wood or termite nests (Marshall, 1989; Kesler and Haig, 2005), not in inaccessible/artificial cavities like Såli. Respondents ranked Sihek intermediate in encounter rate. In their chances of surviving an encounter, both Såli and Sihek were ranked intermediate, but only Sihek went extinct in the wild. The adaptation to urban habitats appears to be a prime reason for Såli's persistence, offering a zone of greatly reduced BTS access and abundance. Såli also have high rates of reproduction (Jenkins, 1983; Pollock et al., 2019) that help compensate for still high rates of BTS predation of young birds.

BTS resistant nest boxes for Såli have greatly improved their predator avoidance and show promise for both Såli and Sihek 
(Savidge et al., 2018). Installing predator-excluding nest boxes into BTS suppressed forests and encouraging Såli expansion may serve as a first trial of introductions/translocations and offer the opportunity to study bird-snake interactions firsthand. These boxes only protect nestlings and incubating adults, however. Fledglings and non-nesting adults would still be vulnerable at night when roosting away from nest boxes if BTS are not sufficiently suppressed (Savidge et al., 2018; Pollock et al., 2019).

For a full assessment of species level risks, the vulnerability metrics we generated here could be integrated in models that consider each bird's entire life cycle. A common result of size (or stage) structured demographic models is that the demographic rates in certain life stages often have disproportionate effects on birds over their life cycles (Saether et al., 2000; Clark and Martin, 2007). As a result, the acute vulnerability in one life stage or in a single demographic process may contribute most to the cumulative lifetime vulnerability (e.g., Cleasby et al., 2017). Reestablishment of a species is a population level phenomenon, and our focus here has been on individual bird-snake interactions. While we did imitate the progression of stage-specific risks that propagate over an idealized lifetime, we did not tailor a life cycle specifically for each species, nor did we define reproduction. Both features would be required for a full demographic model to translate the impact of BTS on a population, which would measure the total vulnerability of a species occurrence. While this goes beyond the scope of our work here, we do show that risks are uneven among life stages. Younger stages are at higher risk in part because they are smaller, but also because they may lack experience or physical abilities that enable escape. However, adults remain at relatively high risk, and the pattern of cumulative lifetime risk among these birds largely reflects risk of death for adult birds encountered by BTS.

The size distribution of BTS in an area is another crucial component in a full risk assessment. Snake size greatly affected our estimates of bird mortality due to BTS encounter, and some current suppression tactics are believed be selective for certain BTS size classes, altering size distributions of BTS (Rodda et al., 2007; Lardner et al., 2009, 2013; Nafus et al., 2020; Siers et al., 2020b). Ultimately, it is the difference in size between a bird and a snake that determines risk of death due to the snake's gape limiting its abilities to seize, restrain, kill, and ingest prey (BTS swallow their prey whole). However, several instances have been documented where a BTS has been able to kill a bird though it was subsequently unable to swallow it (Savidge, 1988; Pollock et al., 2019). Still, the smallest BTS are primarily small lizard specialists (Savidge, 1988; Lardner et al., 2009; Siers, 2015) that typically do not target birds and are therefore of minimal risk regardless of bird size. As snakes grow larger, they add mammals and birds to their diet and it is this middle size class that is most sensitive to control efforts that use toxic dead neonatal mouse baits (Lardner et al., 2009, 2013). Mid-sized BTS may pose the largest risk due to its relative abundance being sustained by high recruitment from the smaller size class (Siers et al., 2017a). Current suppression tools may not be fully effective for very large BTS (Nafus et al., 2020; Goetz et al., 2021; Siers et al., 2021) and may have an effect disproportional to their low abundance (Siers et al., 2017a). With improvements in evaluating BTS contact rates and size distributions (e.g., Siers et al., 2021) our results can help to translate this information into the risk for each bird species under a given level of BTS predation threat.

The quantitative estimates we derived here from expert opinion can be incorporated into more sophisticated probabilistic population models that include species-specific vital rates and can project viability for reintroduced birds on Guam in the presence of BTS. Incorporation of expert opinion into these models would add defensible dimensions of nuance to models that might otherwise be based on potentially naïve assumptions. More broadly, this work contributes to our understanding of predator vulnerability for species that lack natural predators and provides guidance for restoration initiatives that seek to reverse the impacts of invasive predators on endangered species.

\section{DATA AVAILABILITY STATEMENT}

The raw data supporting the conclusions of this article will be made available by the authors, without undue reservation.

\section{ETHICS STATEMENT}

Ethical review and approval was not required for the study on human participants in accordance with the local legislation and institutional requirements. The patients/participants provided their written informed consent to participate in this study. Ethical review and approval was not required for the animal study because we asked scientists about how birds would respond when confronted by snakes, but our research did not involve any direct observation or contact with any animals.

\section{AUTHOR CONTRIBUTIONS}

RM composed the questionnaire, compiled responses, analyzed results, and composed the initial manuscript draft with revisions from all coauthors (SS, EP, and AN). The survey was administered through the University of Guam. SS secured funding. This project was conceived and designed with input from all authors.

\section{FUNDING}

This study was funded by the Department of Defense, United States Marine Corps.

\section{ACKNOWLEDGMENTS}

We were very grateful to the participants in our study: Richard J. Camp, Earl W. Campbell, Robert J. Craig, Evan C. Fricke, William Pitt, Henry Pollock, Martin Kastner, Andria L. Kroner, Paul Radley, Mark J. Rauzon, Robert Reed, 
Evan M. Rehm, Gordon H. Rodda, Linda Santos, Diane L. Vice, Gary J. Wiles, M. J. Mazurek, and Melia Nafus. Any use of trade, firm, or product names is for descriptive purposes only and does not imply endorsement by the U.S. Government.

\section{REFERENCES}

Amidon, F. A., Haas, C. A., and Morton, J. M. (2004). Breeding biology of the endangered Rota Bridled White-eye. Wilson J. Ornithol. 116, 342-346. doi: 10.1676/04-037

Banks, P. B., and Dickman, C. R. (2007). Alien predation and the effects of multiple levels of prey naiveté. Trends Ecol. Evol. 22, 229-230. doi: 10.1016/j.tree.2007.02.006

Berkunsky, I., Kacoliris, F. P., Faegre, S. I., Ruggera, R. A., Carrera, J. D., and Arambur,ú, R. M. (2011). Nest predation by arboreal snakes on cavity nestingbirds in dry Chaco woodlands. Ornitol. Neotrop. 22, 459-464. Available online at: http://sedici.unlp.edu.ar/handle/10915/100926

Brock, M. K., and Beauprez, G. (2000). The rail road to recovery. Endangered Species 25, 7.

Clark, M., and Martin, T. (2007). Modeling tradeoffs in avian life history traits and consequences for population growth. Ecol. Modell. 209, 110-120. doi: 10.1016/j.ecolmodel.2007.06.008

Cleasby, I. R., Bodey, T. W., Vigfusdottir, F., McDonald, J. L., McElwaine, G., Mackie, K., et al. (2017). Climatic conditions produce contrasting influences on demographic traits in a long-distance Arctic migrant. J. Anim. Ecol. 86, 285-295. doi: 10.1111/1365-2656.12623

Fischer, J., and Lindenmayer, D. B. (2000). An assessment of the published results of animal relocations. Biol. Conserv. 96, 1-11. doi: 10.1016/S0006-3207(00)00048-3

Goetz, S. M., Hileman, E. T., Nafus, M. G., Yackel Adams, A. A., Bryant, A. R., Reed, R. N., et al. (2021). Brown Treesnake Mortality Habitat Management Unit Guam 2019. Reston, VA: U.S. Geological Survey.

Haig, S. M., Ballou, J. D., and Derrickson, S. R. (1990). Management options for preserving genetic diversity: reintroduction of Guam rails to the wild. Conserv. Biol. 4, 290-300. doi: 10.1111/j.1523-1739.1990.tb00291.x

Heezik, Y.,v., Seddon, P. J., and Maloney, R. F. (1999). Helping reintroduced houbara bustards avoid predation: effective anti-predator training and the predictive value of pre-release behaviour. Anim. Conserv. 2, 155-163. doi: 10.1111/j.1469-1795.1999.tb00061.x

Jenkins, J. M. (1979). Natural history of the Guam Rail. Condor 81, 404-408. doi: $10.2307 / 1366967$

Jenkins, J. M. (1983). The native forest birds of Guam. Ornithol. Monogr. 31:ii-61. doi: $10.2307 / 40166770$

Kesler, D. C., and Haig, S. M. (2005). Microclimate and nest-site selection in micronesian kingfishers. Pac. Sci. 59, 499-508. doi: 10.1353/psc.2005.0045

Lardner, B., Savidge, J. A., Rodda, G. H., and Reed, R. N. (2009). Prey preferences and prey acceptance in juvenile brown treesnakes (Boiga irregularis). Herpetol. Conserv. Biol. 4, 313-323.

Lardner, B., Yackel Adams, A. A., Savidge, J. A., Rodda, G. H., Reed, R. N., and Clark, C. S. (2013). Effectiveness of bait tubes for Brown Treesnake control on Guam. Wildl. Soc. Bull. 37, 664-673. doi: 10.1002/wsb,.297

MAC Working Group (2014). Marianas Avifauna Conservation (MAC) Plan: Long-Term Conservation Plan for the Native Forest Birds of the Northern Mariana Islands (Revised). Honolulu: CNMI Division of Fish and Wildlife, Saipan, and U.S.

Marshall, S. D. (1989). Nest sites of the Micronesian Kingfisher on Guam. Wilson Bull. 101, 472-477.

Martin, T. G., Burgman, M. A., Fidler, F., Kuhnert, P. M., Low-Choy, S., McBride, M., et al. (2012). Eliciting expert knowledge in conservation science. Conserv. Biol. 26, 29-38. doi: 10.1111/j.1523-1739.2011.01806.x

Moseby, K., Read, J., Paton, D., Copley, P., Hill, B., and Crisp, H. (2011). Predation determines the outcome of 10 reintroduction attempts in arid South Australia. Biol. Conserv. 144, 2863-2872. doi: 10.1016/j.biocon.2011.08.003

\section{SUPPLEMENTARY MATERIAL}

The Supplementary Material for this article can be found online at: https://www.frontiersin.org/articles/10.3389/fcosc. 2021.683964/full\#supplementary-material

Nafus, M. G., Yackel Adams, A. A., Boback, S. M., Siers, S. R., and Reed, R. N (2020). Behavior, size, and body condition predict susceptibility to management and reflect post-treatment frequency shifts in an invasive snake. Glob. Ecol. Conserv. 21:e00834. doi: 10.1016/j.gecco.2019.e00834

Nietmann, L., and Ha, R. R. (2018). Variation in age-dependent nest predation between island and continental Rufous Fantail (Rhipidura rufifrons) subspecies. Auk Ornithol. Adv. 135, 1064-1075. doi: 10.1642/AUK-18-40.1

Norbury, G. L., Price, C. J., Latham, M. C., Brown, S. J., Latham, A. D. M., Brownstein, G. E., et al. (2021). Misinformation tactics protect rare birds from problem predators. Sci. Adv. 7, 1-8. doi: 10.1126/sciadv.abe4164

Plentovich, S., Morton, J. M., Bart, J., Camp, R. J., Lusk, M., Johnson, N., et al. (2005). Population trends of Mariana Crow Corvus kubaryi on Rota, Commonwealth of the Northern Mariana Islands. Bird Conserv. Int. 15, 211-224. doi: 10.1017/S095927090500016X

Pollock, H. S., Kastner, M., Wiles, G. J., Thierry, H., Barnhart Dueñas, L., Paxton, E. H., et al. (2021). Recent recovery and expansion of Guam's locally endangered Såli (Micronesian Starling) Aplonis opaca population in the presence of the invasive brown treesnake. Bird Conserv. Int. 1-16. doi: 10.1017/S0959270920000726

Pollock, H. S., Savidge, J. A., Kastner, M., Seibert, T. F., and Jones, T. M. (2019). Pervasive impacts of invasive brown treesnakes drive low fledgling survival in endangered Micronesian Starlings (Aplonis opaca) on Guam. Condor 121, 1-11. doi: 10.1093/condor/duz014

Rodda, G. H., and Reed, R. N. (2007). "Size-based trends and management implications of microhabitat utilization by brown tree snakes, with an emphasis on juvenile snakes," in Managing Vertebrate Invasive Species: Proceedings of an International Symposium, eds G. W. Witmer, W. C. Pitt, and K. A. Fagerstone (Fort Collins, CO: USDA/APHIS Wildlife Services, National Wildlife Research Center), 257-267.

Rodda, G. H., and Savidge, J. A. (2007). Biology and impacts of Pacific Island invasive species. 2. Boiga irregularis, the Brown Tree Snake (Reptilia: Colubridae). Pac. Sci. 61, 307-324. doi: 10.2984/1534-6188(2007)61(307:BAIOPI)2.0.CO;2

Rodda, G. H., Savidge, J. A., Tyrrell, C. L., Christy, M. T., and Ellingson, A. R. (2007). Size bias in visual searches and trapping of brown treesnakes on Guam. J. Wildl. Manage. 71, 656-661. doi: 10.2193/2005-742

Runge, M. C., Converse, S. J., and Lyons, J. E. (2011). Which uncertainty? using expert elicitation and expected value of information to design an adaptive program. Biol. Conserv. 144, 1214-1223. doi: 10.1016/j.biocon.2010.12.020

Saether, B.-E., Engen, S., Lande, R., Arcese, P., and Smith, J. N. M. (2000). Estimating the time to extinction in an island population of song sparrows. Proc. Biol. Sci. 267, 621-626. doi: 10.1098/rspb.2000.1047

Savidge, J. A. (1987). Extinction of an island forest avifauna by an introduced snake. Ecology 68, 660-668. doi: 10.2307/1938471

Savidge, J. A. (1988). Food habits of Boiga irregularis, an introduced predator on Guam. J. Herpetol. 275-282. doi: 10.2307/1564150

Savidge, J. A., Kastner, M., and Seibert, T. F. (2018). Developing a PredatorResistant Nest Box for Micronesian Starlings with application to Endangered Guam Micronesian Kingfishers Final Report. Santa Rita: U.S. Department of Navy, NAVFAC Marianas.

Siers, S., Goetz, S., Volsteadt, R., and Nafus, M. (2021). Evaluating lethal toxicant doses for the largest individuals of an invasive vertebrate predator with indeterminate growth. Manag. Biol. Invasions 12, 476-494. doi: 10.3391/mbi.2021.12.2.17

Siers, S. R. (2015). Microgeographic and ontogenetic variability in the ecology of invasive brown treesnakes on Guam, and effects of roads on their landscape-scale movements (Dissertation dissertation). Colorado State University, Fort Collins, CO, United States. 
Siers, S. R. (accepted). Allometric regression of snake body length from head image measurements. Wildl. Soc. Bull. (in press).

Siers, S. R., Eisemann, J. D., Pitt, W. C., Clark, L., Goetz, S. M., Gosnell, R. J., et al. (2020a). "Automated aerial baiting for invasive brown treesnake control: system overview and program status," in Proceedings of the Vertebrate Pest Conference, ed D. M. Woods (Santa Barbara, CA).

Siers, S. R., Savidge, J. A., and Reed, R. N. (2017a). Ontogenetic and ecological variation in invasion risk of Brown Treesnakes (Boiga irregularis) on Guam. Manag. Biol. Invasions 8, 469-483. doi: 10.3391/mbi.2017.8.4.02

Siers, S. R., Savidge, J. A., and Reed, R. N. (2017b). Quantile regression of microgeographic variation in population characteristics of an invasive vertebrate predator. PLoS ONE 12:e0177671. doi: 10.1371/journal.pone.0177671

Siers, S. R., Shiels, A. B., and Barnhart, P. D. (2020b). Invasive snake activity before and after automated aerial baiting. J. Wildl. Manage. 84, 256-267. doi: 10.1002/jwmg. 21794

Sutherland, W. J. (2006). Predicting the ecological consequences of environmental change: a review of the methods. J. Appl. Ecol. 43, 599-616. doi: 10.1111/j.1365-2664.2006.01182.x

Trask, A., Ferrie, G., Wang, J., Newland, S., Canessa, S., Moehrenschlager, A., et al. (2021). Multiple life-stage inbreeding depression impacts demography and extinction risk in an extinct-in-the-wild species. Sci. Rep. 11:682. doi: $10.1038 /$ s41598-020-79979-4

U.S. Fish and Wildlife Service (2005). Draft Revised Recovery Plan for the Aga or Mariana Crow, Corvus kubaryi. Portland, OR: U.S. Fish and Wildlife Service.

West, R., Letnic, M., Blumstein, D. T., and Moseby, K. E. (2018). Predator exposure improves anti-predator responses in a threatened mammal. J. Appl. Ecol. 55, 147-156. doi: $10.1111 / 1365-2664.12947$
White, T. H. Jr., Collazo, J. A., and Vilella, F. J. (2005). Survival of captive-reared Puerto Rican parrots released in the Caribbean National Forest. Condor 107, 424-432. doi: 10.1093/condor/107.2.424

Wiles, G. J., Bart, J., Beck, R. E. Jr., and Aguon, C. F. (2003). Impacts of the brown tree snake: patterns of decline and species persistence in Guam's avifauna. Conserv. Biol. 17, 1350-1360. doi: 10.1046/j.1523-1739.2003. 01526.x

Yackel Adams, A. A., Nafus, M. G., Klug, P. E., Lardner, B., Mazurek, M., Savidge, J. A., et al. (2019). Contact rates with nesting birds before and after invasive snake removal: estimating the effects of trap-based control. NeoBiota 49, 1-17. doi: $10.3897 /$ neobiota.49.35592

Zarones, L., Sussman, A., Morton, J. M., Plentovich, S., Faegre, S., Aguon, C., et al. (2015). Population status and nest success of the Critically Endangered Mariana crow Corvus kubaryi on Rota, Northern Mariana Islands. Bird Conserv. Int. 25, 220-233. doi: 10.1017/S09592709140 00045

Conflict of Interest: The authors declare that the research was conducted in the absence of any commercial or financial relationships that could be construed as a potential conflict of interest.

Copyright (๑) 2021 McElderry, Paxton, Nguyen and Siers. This is an open-access article distributed under the terms of the Creative Commons Attribution License (CC $B Y)$. The use, distribution or reproduction in other forums is permitted, provided the original author(s) and the copyright owner(s) are credited and that the original publication in this journal is cited, in accordance with accepted academic practice. No use, distribution or reproduction is permitted which does not comply with these terms. 